\title{
Learning from a provisioning site: code of conduct compliance and behaviour of whale sharks in Oslob, Cebu, Philippines
}

Anna Schleimer, Gonzalo Araujo, Luke Penketh, Anna Heath, Emer McCoy, Jess Labaja, Anna Lucey, Alessandro Ponzo

While shark-based tourism is a rapidly growing global industry, there is ongoing controversy about the effects of provisioning on the target species. This study investigated the effect of feeding on whale sharks (Rhincodon typus) at a provisioning site in Oslob, Cebu, in terms of arrival time, avoidance and feeding behaviour using photo-identification and focal follows. Additionally, compliance to the code of conduct in place was monitored to assess tourism pressure on the whale sharks. Newly identified sharks gradually arrived earlier to the provisioning site after their initial sighting, indicating that the animals learn to associate the site with food rewards. Whale sharks with a long resighting history showed anticipatory behaviour and were recorded at the site on average 5 minutes after the arrival of feeder boats. Results from a generalised linear mixed model indicated that animals with a longer resighting history were less likely to show avoidance behaviour to touches or boat contact. Similarly, sequential data on feeding behaviour was modelled using a generalised estimating equations approach, which suggested that experienced whale sharks were more likely to display vertical feeding behaviour. It was proposed that the continuous source of food provides a strong incentive for the modification of behaviours, i.e. learning, through conditioning. Whale sharks are large opportunistic filter feeders in a mainly oligotrophic environment, where the ability to use novel food sources by modifying their behaviour could be of great advantage. Non-compliance to the code of conduct in terms of minimum distance to the shark $(2 \mathrm{~m})$ increased from $79 \%$ in 2012 to $97 \%$ in 2014, suggesting a high tourism pressure on the whale sharks in Oslob. The longterm effects of the observed behavioural modifications along with the high tourism pressure remain unknown. However, management plans are traditionally based on the precautionary principle, which aims to take preventive actions even if data on cause and effect are still inconclusive. Hence, an improved enforcement of the code of conduct coupled with a reduction in the conditioning of the whale sharks through provisioning were proposed to minimise the impacts on whale sharks in Oslob. 
Learning from a Provisioning Site: Code of Conduct Compliance and Behaviour of Whale Sharks in Oslob, Cebu, Philippines

Anna Schleimer ${ }^{1,2}$, Gonzalo Araujo ${ }^{1}$, Luke Penketh ${ }^{1}$, Anna Heath ${ }^{1}$, Emer McCoy ${ }^{1}$, Jessica Labaja $^{1}$, Anna Lucey ${ }^{1} \&$ Alessandro Ponzo ${ }^{1,3}$

${ }^{1}$ Large Marine Vertebrates Research Institute Philippines, Jagna, Bohol, Philippines

2 ODYSSEA Marine Research and Awareness, Diekirch, Luxembourg

${ }^{3}$ Physalus NGO, Large Marine Vertebrates Project Philippines, Largo Callifonte, Rome, Italy

Corresponding author: Anna Schleimer, anna.schleimer@odyssea.lu 
1 Abstract: While shark-based tourism is a rapidly growing global industry, there is ongoing 2 controversy about the effects of provisioning on the target species. This study investigated the 3 effect of feeding on whale sharks (Rhincodon typus) at a provisioning site in Oslob, Cebu, in 4 terms of arrival time, avoidance and feeding behaviour using photo-identification and focal 5 follows. Additionally, compliance to the code of conduct in place was monitored to assess 6 tourism pressure on the whale sharks. Newly identified sharks gradually arrived earlier to the 7 provisioning site after their initial sighting, indicating that the animals learn to associate the site and were recorded at the site on average 5 minutes after the arrival of feeder boats. Results from a generalised linear mixed model indicated that animals with a longer resighting history were less likely to show avoidance behaviour to touches or boat contact. Similarly, sequential data on feeding behaviour was modelled using a generalised estimating equations approach, which suggested that experienced whale sharks were more likely to display vertical feeding behaviour. It was proposed that the continuous source of food provides a strong incentive for the modification of behaviours, i.e. learning, through conditioning. Whale sharks are large opportunistic filter feeders in a mainly oligotrophic environment, where the ability to use novel food sources by modifying their behaviour could be of great advantage. Non-compliance to the code of conduct in terms of minimum distance to the shark $(2 \mathrm{~m})$ increased from $79 \%$ in 2012 to $97 \%$ in 2014, suggesting a high tourism pressure on the whale sharks in Oslob. The long-term effects of the observed behavioural modifications along with the high tourism pressure remain unknown. However, management plans are traditionally based on the precautionary principle, which aims to take preventive actions even if data on cause and effect are still inconclusive. Hence, an improved enforcement of the code of conduct coupled with a reduction in the conditioning of the whale sharks through provisioning were proposed to minimise the impacts on whale sharks in Oslob.

\section{Introduction}

Shark-based tourism is a rapidly growing global industry (Gallagher and Hammerschlag 2011). With its economic benefits extending throughout the community, shark-based tourism has allowed some communities to improve their economic status (Quiros 2007; Brunnschweiler 2010; Gallagher and Hammerschlag 2011; Vianna et al. 2012). Despite numerous advantages of managing shark species as a non-consumptive resource for both the target species and local communities, the appropriateness of the term 'non-consumptive' has been questioned in recent years (Gallagher et al. 2015). Initially a non-consumptive activity relating to wildlife recreation was defined as "human recreational engagement with wildlife wherein the focal animal is not purposefully removed or permanently affected by the engagement" (Duffus and Dearden 1993). The potential effects of shark-based tourism on the focal species and its ecosystem have been the 
37 topic of considerable debate, especially when provisioning through chumming, baiting or feeding

occurs (Orams 2002; Gallagher et al. 2015, Brena et al. in press). Proposed impacts of provisioning in elasmobranchs include direct impacts on the physiology or behaviour of the provisioned animals as well as indirect effects, cascading through the ecosystem by altering predator-prey interactions through changes in predator abundance or composition at the feeding site (Orams 2002; Brunnschweiler and Baensch 2011; Brunnschweiler et al. 2014). However, while direct effects of provisioning were reported for some elasmobranch species (Semeniuk and Rothley 2008; Semeniuk et al. 2009; Clua et al. 2010; Fitzpatrick et al. 2011), other studies found no evidence for behaviourally mediated effects of provisioning at large spatial and temporal scales (Hammerschlag et al. 2012). Furthermore, lack of data precludes determination of ecosystem-wide impacts mediated by provisioning (Burgin and Hardiman 2015). Maljković \& Côté (2011) suggested that the amount of food provided to Caribbean reef sharks (Carcharhinus perezi) was insufficient to meet their daily requirement and that provisioning was unlikely to alter their role as apex predators in the ecosystem. Despite considerable research in the recent years, no general trend about the reported effects of provisioning on shark species seems to be obvious; in contrast, effects appear to be species, context and site dependent and generalisations across provisioning sites may result in a distorted image of the true effects (Brunnschweiler and Barnett 2013; Gallagher et al. 2015; Burgin and Hardiman 2015; Brena et al. in press).

However, while the scientific community has yet to come to a consensus about the effects of shark-based tourism on the target species, it has been acknowledged that feeding sites can offer a unique opportunity to study the behaviour of these otherwise elusive species (Hammerschlag et al. 2012). The unsuitability of studying large elasmobranch species in a captive environment, and time-consuming and costly field experiments, have resulted in a lack of knowledge on cognitive abilities in elasmobranchs compared to other vertebrates (Guttridge et al. 2009; Schluessel 2015). The direct response of sharks to tourism is commonly assessed using an ethological approach, based on direct observations of behaviours (Pierce et al. 2010; Guttridge and Brown 2014; Haskell et al. 2014). By creating a descriptive catalogue of behaviours, the so-called ethogram, the occurrence of various behaviours can be assessed in relation to certain stimuli (Gruber and Myrberg 1977). Provisioning sites can offer frequent and predictable encounters with the target species, as well as close interactions, and pre-existing infrastructures. However, the artificial nature of such sites should be taken into account because behaviours occurring at these sites may not be representative of natural behaviours or grouping patterns (Semeniuk and Rothley 2008).

Additionally, sharks are often confronted with completely novel situations and stimuli at provisioning sites, offering a valuable insight into the learning capacities of these species (Guttridge et al. 2009). Learning is defined as the adaptive modification of behaviour based on experience, allowing an animal to develop, within its lifetime, an adaptive response to a novel situation that has potentially never been encountered in the species' evolutionary past (Kawecki 2010; Gallagher et al. 2015). In the case of repeated exposure to stimuli, learning can occur either through learning an association or relationship between two events, known as associative 
learning (e.g. conditioning or observational learning) or by non-associative learning, where a single stimulus leads to habituation or sensitisation (Lieberman 2000). Results from previous studies indicate that the cognitive abilities in elasmobranchs are as well developed as in teleosts or other vertebrates (Schluessel 2015). Their ability to learn, habituate, and remember spatial maps was suggested to facilitate efficient foraging, predator avoidance, habitat selection and mate choice in a dynamic environment (Guttridge et al. 2009; Schluessel 2015). However, many unanswered questions still remain about basic principles of shark learning, notably whether any intra- or interspecific differences in learning exist, where shark learning capabilities fit in with other vertebrates, and how long sharks can memorise associations (Guttridge et al. 2009).

In this study, we used the setting of a provisioning site to gain insight into the learning capacity of the whale shark (Rhincodon typus). We hypothesised that learning plays an important role when assessing the impact of tourism on elasmobranchs and that the animals' capacity to learn (e.g. through conditioning and habituation) needs to be taken into account when developing regulations for human-shark interactions. Current management plans of shark tourism rely on compliance to codes of conduct, which have been implemented by the majority of shark tourism operators as a precautionary procedure to mitigate potential negative impacts on sharks and guests (Richards et al. 2015). Codes of conduct aim to regulate human behaviour during shark interactions, in terms of maximum people per shark, minimum distance to the shark, and general practices such as no touching or flash photography (Richards et al. 2015). However, despite the observation of widely site- and species-specific effects of nature-based tourism on sharks, only some codes of conduct are the direct product of site-specific scientific studies (e.g. Pierce et al. 2010). Additionally, poor enforcement and impracticality may lead to low compliance to these codes of conduct (Quiros 2007; Smith et al. 2010).

This study investigated the adaptive behavioural response of whale sharks to novel stimuli at a provisioning site, with particular emphasis on learning processes over time and the potential importance of learning when developing codes of conduct. Firstly, changes in tolerance levels to perceived disturbance at the provisioning site were evaluated. The setting allowed sequential sampling of the same individuals exposed to different levels of disturbance, hence allowing to detect potential habituation or sensitisation processes (Bejder et al. 2009). Secondly, we examined the occurrence of associative learning in the provisioned whale sharks. The repeated exposure to food rewards was expected to lead to conditioning in sharks through positive reinforcement when the correct voluntary behaviour was displayed. Specifically, changes in feeding behaviour as well as time of arrival to the provisioning site were investigated over time. Compliance to a code of conduct was considered to act as a proxy for tourism pressure (Quiros 2007) and was discussed within the context of the behavioural modifications observed in the whale sharks.

\section{Methods}


113 The methods presented here were conducted in accordance with national and local laws in

114 respect of animal welfare. The Bureau of Fisheries and Aquatic Resources - Region 7, issued the 115 authors a Gratuitous Permit (NO.01-2013), and a Memorandum of Agreement was signed with 116 the Department of Environment and Natural Resources and DA-BFAR7. The Municipality of 117 Oslob granted the authors a Prior Informed Consent document.

\section{2.1 Study site}

119 The study site was located in the coastal waters off Barangay Tan-Awan, Municipality of Oslob, 120 Cebu Province, Philippines. The provisioning of whale sharks occurs within an interaction area 121 of about $65,000 \mathrm{~m}^{2}$, located about $50 \mathrm{~m}$ from shore, as described and illustrated by Araujo et al. (2014). The municipal government has granted permission to provision whale sharks only to members of the Tan-Awan Oslob Whale Shark Fishermen Association (TOWSFA). Year-round, feeders on one-man paddleboats provision the animals from 6 am to $1 \mathrm{pm}$, using up to $150 \mathrm{~kg}$ of food daily, depending on shark and tourist numbers. The food consists mainly of sergestid shrimp, which is locally known as uyap. Same as the provisioning, the interaction with whale sharks is only allowed between 6 am and $1 \mathrm{pm}$ and no whale shark watcher is allowed in the interaction area outside those times. Tourists receive a briefing on the interaction guidelines prior to their whale shark watching and are taken to the interaction area on paddleboats of approx. 5 $\mathrm{m}$, carrying up to 12 people for 30 minutes of whale shark watching. Once the tourist boats are aligned by tying to neighbouring boats, tourists can choose to enter the water and either hold on to the boat or snorkel with the whale sharks. Feeders lure the whale sharks with food along the line of tourist boats. On days without current, tourist boat formation may be of a more random nature and circles of boats around sharks have been observed. Scuba divers already on boats when arriving to the interaction area are not required to pass through the briefing centre on land, instead the ordinance states that the orientation should be conducted onboard. Scuba divers are dropped from the motor boats moored outside the interaction area for an interaction of up to an hour.

\subsection{Code of Conduct}

The code of conduct for the whale shark activities taking place in the municipal waters of Oslob, Cebu, was approved as a municipal ordinance on 6 Jan 2012, and further amended on 12 April 2012. The ordinance states that whale shark watching is limited to a thirty-minute interaction. Tourists are not allowed to stay within 5 meters directly beside or behind the caudal fin and within 2 meters in front of the whale shark. Additionally, a maximum of six whale shark watchers (i.e. snorkelers or boat-holders) and four scuba divers per whale shark are permitted at any one time. Heavy splashing, riding, touching using hands, feet, camera or pointers are strictly prohibited. Compliance with the code of conduct was assessed by investigating the number of instances in which swimmers, boat-holders, and scuba divers were observed within $2 \mathrm{~m}$ of the whale shark during focal follows. While tourists are supposed to keep a $5 \mathrm{~m}$ distance from the flanks and caudal fin of the whale shark, the $2 \mathrm{~m}$ limit, corresponding to about a human body 
151 length, was considered a definite infraction of the code of conduct and excludes the people that

152 are just marginally breaking the code of conduct. The total number of people within $10 \mathrm{~m}$ of the

153 whale shark was used to assess the compliance with the recommended number of people per

154 shark. While the ordinance states the maximum number of people per shark, it does not explicitly

155 describe the distance at which an observer is considered interacting with the shark. Instead the 10

$156 \mathrm{~m}$ limit was chosen based on the feasibility of counting the number of people accurately with

157 varying degrees of visibility during the seasons.

158

159

160

161

162

163

164

165

166

167

168

169

170

171

172

173

174

175

176

177

178

179

180

181

182

183

184

185

186

187

188

\subsection{Behavioural surveys}

Researchers conducted in-water surveys with the aim to record both behaviour of whale sharks and compliance of tourists and boatmen to the code of conduct. Each in-water survey lasted for 20 minutes during which a single shark was followed. Focal follows are a commonly used field method to sample behaviours of readily identifiable individuals or groups (Altmann 1974; Mann and Würsig 2014). Upon entering the interaction area, the first shark seen was chosen as the focal follow shark to ensure random sampling of animals. Data collected during each 20 -minute segment included tourist numbers, shark behaviour, and other events, such as shark contact. Data on tourist numbers were collected every 5 minutes and consisted of snorkelers and boat-holders within $2 \mathrm{~m}$ of the shark, total number of tourists (snorkelers and boat-holders) within $10 \mathrm{~m}$ of the shark, and scuba divers within $2 \mathrm{~m}$ and $10 \mathrm{~m}$ of the shark. Additionally the number of other sharks within $10 \mathrm{~m}$ was recorded. The predominant behaviour of the shark was recorded every 5 minutes based on predefined categories: horizontal feeding (HF), vertical feeding (VF), free swimming (FS), or natural feeding (NF; Table 1). Additionally active and passive guest contacts, boat contacts and shark-to-shark contacts were recorded with the subsequent reactions as they happened (Table 1). Reactions to such events were categorised as no response, swimming away, circling behaviour, switching feeder boats, and thrashing of the body (Table 1). If a shark swam out of sight during a focal follow, the session was ended if the shark was not relocated within 3 minutes.

Each focal follow shark was identified using photo-identification (photo-ID) of the unique spot pattern behind the gill slits and above the pectoral fin on the left side of the body. Photo-ID on whale sharks has been successfully used for the study of residence patterns (Araujo et al. 2014), to estimate survival (Bradshaw et al. 2007), and to investigate scarring patterns and mortality rates (Speed et al. 2008). Additionally, animals were sexed by the absence (females) or presence (males) of pelvic claspers (Araujo et al. 2014). The size of the shark was visually estimated by the researcher, a method which has been previously validated using measurements from laser photogrammetry for comparison (Araujo et al. 2014).

Upon arrival to the study site, the time of the first feeder boats as well as first shark observed from an outlook on land were noted. Binoculars were used to either spot dorsal or caudal fins or the shadow of a shark under the water surface. When the researcher entered the water at 6 am by snorkelling out to the interaction area from shore, photo-ID pictures of the first shark sighted in 
189

190

191

192

193

194

195

196

197

198

199

200

201

202

203

204

205

206

207

208

209

210

211

212

213

214

215

216

217

218

219

220

221

222

223

224

225

226

227

water were recorded along with the time of this first sighting. These data were used to assess when sharks arrived at the study site relative to the onset of feeding and to test whether past sighting history affected time of arrival. Additionally, shark presence was recorded during every hourly photo-ID session from 6 am to 1 pm from February 2014 onwards (see Araujo et al. 2014 for details). Photo-ID pictures allowed the identification of individual sharks or the assignment of a new identification number in case the whale shark was not found in the ongoing photo-ID catalogue by two experienced researchers. In addition to the local identification number, pictures of each shark were uploaded to the international online whale shark database 'Wildbook' on www.whaleshark.org, where an international identification number was assigned to each individual. The number of session in which a previously unidentified shark was observed was extracted from the photo-ID dataset to assess whether new sharks were more likely to be sighted at a certain time of day.

\subsection{Data analysis}

A binomial Generalised Linear Mixed Model (GLMM) was fitted to investigate which factors affect avoidance behaviour. GLMMs are a combination of linear mixed models, allowing the incorporation of random effects, and generalised linear models, which apply link functions and exponential families to deal with non-normal data (Bolker et al. 2009). Avoidance behaviour was coded as a binary response, where no reaction to event was reported as 0 and behaviours such as swimming off, banking, eye roll, diving and change in direction were marked as 1 . Potential explanatory variables included the event (Table 1), predominant behaviour, number of previous sightings (i.e. number of confirmed daily sightings of the individual shark), sex, estimated size, current, visibility, and number of swimmers within $10 \mathrm{~m}$ of the shark. Current was measured on a scale of 1 to 4 ( 1 = no current, 2 = researcher requires effort to swim, 3 = researcher experiences difficulty to swim against current, $4=$ researcher cannot swim against current). Visibility was recorded as the maximum distance in meters from which a researcher could confidently identify a whale shark from the spot patterns. Due to problems of model convergence, the variable 'previous number of visits' was rescaled by dividing through the interquartile range (Babyak 2009). Shark ID was added as a random effect to avoid pseudoreplication, which occurs when replicates are not statistically independent (Hurlbert 1984; Dawson and Lusseau 2005). Free swimming and passive touch were specified as the reference baseline levels, because sharks were expected to be less likely to show avoidance behaviour while feeding and in response to minor disturbance. Model selection was based on single term deletion, which drops one explanatory variable, in turn, and each time applies an analysis of deviance test (Zuur et al. 2009). GLMM parameters were estimated using Laplace approximations. Models were refitted until all explanatory variables were significant with $p<$ 0.05 using the lme4 package in $\mathrm{R}$ (Bates et al. 2014).

While errors were assumed to be independent for the avoidance behaviour data, which were logged as they occurred throughout the focal follow, data on predominant behaviour were collected systematically every 5 minutes during focal follows and were therefore prone to 
228

229

230

231

232

233

234

235

236

237

238

239

240

241

242

243

244

245

246

247

248

249

250

251

252

253

254

255

256

257

258

259

260

261

262

263

264

temporal autocorrelation. Falsely assuming independence can lead to invalid significance tests, because standard errors and $p$-values tend to be too small and irrelevant explanatory variables may be falsely kept in the models (Panigada et al. 2008; Bailey et al. 2013). Generalised estimating equations (GEEs) account for temporal autocorrelation and were considered the most appropriate models to analyse behavioural data collected during repeated focal follows (Liang and Zeger 1986; Bailey et al. 2013). More specifically, the unrealistic assumption of constant error variance is replaced with a correlation structure in GEEs. In this case, errors were allowed to be correlated within data collected from the same individual. The occurrence of vertical feeding was modelled using a marginal GEE approach with a binomial error distribution and logit link function. Shark ID was defined as a block of data, within which observations were temporally autocorrelated, using the auto-regressive correlation structure. GEEs yield consistent estimates even with misspecification of the working correlation matrix (Liang and Zeger 1986). Explanatory variables that were considered for inclusion into the model included number of previous visits, visibility, current, whale shark sex and size. GEEs were fitted using the package geepack version 3.1.3. (Yan 2002; Højsgaard et al. 2006) in R version 3.1.1 (R Core Team 2014). Model selection was based on backward selection using analysis of deviance tests (Zuur et al. 2009).

In order to investigate whether the first shark recorded every morning at the onset of feeding had a longer resight history compared to sharks never reported as first shark of the day, a Welch two sample t-test was run to compare the number of visits between both groups i.e. first sharks and non-first sharks. A Chi-square test was used to compare the total number of newly identified sharks spotted in each hourly photo-ID session (6-7, 7-8, 8-9, 9-10, 10-11, 11-12, 12-13). Additionally, new sharks that had over 10 resightings within 20 days of their first sighting at the study site, and therefore showing repeated visitation at the study site, were chosen to investigate changes in time of arrival. For all statistical analyses the level of significance was set at $p<0.05$.

\section{Results}

\subsection{Data summary}

From 31 March 2012 to 20 June 2014, a total of 171 individual whale sharks were identified, of which 59 sharks were followed, leading to 1109 focal follow surveys. These surveys typically lasted 20 minutes, but on 27 occasions, surveys were terminated prematurely when the whale shark swam out of sight and was not resighted within the following 3 minutes. These 27 surveys were excluded from further compliance analysis leaving data from 672 focal follows in 2012 , 291 in 2013 and 119 in 2014. The remaining 1082 complete focal follow surveys added up to circa 357 hours worth of data. Some individuals showed very high site fidelity to the feeding site, allowing sequential sampling of the same individuals over a prolonged time period, with 18 individuals being subject to focal follows in at least two consecutive years. A full description of resight histories and visitation patterns are given by Araujo et al. 2014. 


\subsection{Compliance}

Compliance to the required minimum distance from the shark was investigated during the 1082 complete focal follows. During 907 focal follows (84 \%) at least one snorkeler or boat-holder was observed being less than $2 \mathrm{~m}$ away from the whale shark, inconsistent with the code of conduct (Table 2). On average there were 1.9 snorkelers or boat-holders (S.D. $=2.6$ ) and 0.2 scuba divers (S.D. $=0.9$ ) within $2 \mathrm{~m}$ of the whale shark recorded every $5 \mathrm{~min}$. The maximum number of snorkelers and boat-holders around a single shark was observed on 7 September 2013 when 19 people were recorded within $2 \mathrm{~m}$ of a whale shark and, respectively, on 10 December 2012 when 10 scuba divers were closer than $2 \mathrm{~m}$ from the shark.

Data on the number of guests within $10 \mathrm{~m}$ of sharks was missing from 62 focal follows in 2012 , the remaining 1020 focal follows showed that in $56,1 \%$ of the surveys the maximum number of snorkelers allowed per shark (i.e. 6) was exceeded (Fig 1). The maximum number of snorkelers and boat-holders within $10 \mathrm{~m}$ of a shark was 33. Records of the number of scuba divers within $10 \mathrm{~m}$ of a shark only started in July 2013. During these 406 focal follows, the maximum of 4 scuba divers was exceeded on 79 occasions (19.5\%). Twenty-one scuba divers within $10 \mathrm{~m}$ of a shark was the highest number of divers recorded per shark.

From May 2012 to January 2013, researchers systematically counted the amount of active touches from guests and feeders on sharks. A total of 4832 active touches were recorded over 545 focal follows. Feeders pushing away sharks with their feet or petting the sharks with their hands accounted for the majority of these active contacts (97,6\%); while guests were observed touching sharks 117 times. During the 2013 and 2014 survey seasons, feeder touches were no longer systematically counted, because of the lack of reaction observed in the whale sharks. On 114 occasions guests were recorded to actively touch whale sharks during this same period.

\subsection{Avoidance Behaviour}

On 232 occasions since 2012, events such as active touches, boat contact, shark-to-shark contact and passive touches were recorded with the corresponding response of the shark (reaction/no reaction). The occurrence of avoidance behaviour was significantly influenced by the number of the shark's previous visits $\left(\chi^{2}(1, \mathrm{~N}=232)=4.31, p=0.038\right)$, the behaviour at the time of the event $\left(\chi^{2}(2, \mathrm{~N}=232)=16.26, p<0.001\right)$ and the event that caused the response $\left(\chi^{2}(4, \mathrm{~N}=232)\right.$ $=25.79, p<0.001)$. Sharks were less likely to show avoidance when they were vertical or horizontal feeding and had a long history of sightings (Table 3, Fig 2). The odds of observing a behavioural response increased when sharks were free swimming and had a short history of sightings. The event that elicited the strongest response was shark-to-shark contact, while passive contact had little effect.

\subsection{Effect of provisioning on feeding pattern}


300

301

302

303

304

305

306

307

308

309

310

311

312

313

314

315

316

317

318

319

320

321

322

323

324

325

326

327

328

329

330

331

332

333

334

335

336

337

A total of 357 hours of focal follow observations were collected on 59 different sharks. The main behaviour observed in the whale sharks at the provisioning site was vertical feeding $(58.2 \%)$, followed by horizontal feeding $(21.8 \%)$ and free swimming $(20.2 \%)$, while natural feeding only accounted for $0.02 \%$ of all observations. The GEE indicated that the number of previous visits, as well as the current were significant predictors of observing vertical feeding (Table 4, Fig 3). The estimated autocorrelation parameter of $0.41(\mathrm{SE}=0.03)$ indicates moderate autocorrelation, and justified our use of the GEE approach.

\subsection{Trends in shark arrival}

Records of shark session presence during each individual 1 hour session from 6 am to $1 \mathrm{pm}$ started in February 2014, since when 51 new sharks were identified and added to the photo identification catalogue. These new sharks were more likely to be encountered during the later survey sessions, with the highest number of new sharks $(\mathrm{N}=16)$ identified in the last session from $12-1 \mathrm{pm}(\chi 2(6)=16.67, p=0.01$; Fig 4). Only 3 new sharks were identified during the very first session from 6-7 am. However, one of these sharks was anecdotally identified through photo-ID in the area prior to the start of our records. After their initial sighting, newly identified sharks tend to arrive at the interaction area progressively earlier (Fig 5). During the first session from 6-7 am sharks were spotted from land on average 5 minutes after the feeder boats entered the interaction area. The first sharks to be identified in water every morning had a statistically significantly longer history of sightings compared to sharks that have never been reported as first sharks $\left(\mathrm{T}_{31.25}=6.15, p<0.001\right)$. The average number of visits of "first" sharks was 328.5 compared to 19.1 visits of sharks never observed as first shark.

\section{Discussion}

This study highlights the effects of provisioning on the feeding and avoidance behaviour of whale sharks, while using the particular setting of a provisioning site to gain an insight into learning capacities of whale sharks. Results provide evidence for both associative learning, in terms of associating the study site with food and adapting their feeding behaviour, and habituation, in terms of increasing tolerance levels in response to proximity of people and other sharks.

At the time of writing, 821 individuals were identified on "Wildbook for Whale Sharks" in the Philippines, with natural aggregations occurring in Donsol, Sorsogon Province, and Pintuyan, Southern Leyte, but sightings are reported country-wide (Quiros 2007; Araujo et al. 2014). A long history of fishery and trade of whale sharks in the Bohol Sea and satellite telemetry data confirm their natural occurrence in these waters (Alava et al. 2002; Eckert et al. 2002). However, it remains unknown how individuals recruit into the artificial feeding aggregation at the provisioning site in Oslob and how many sharks frequented the area before the beginning of the provisioning activities (Araujo et al. 2014). Our observations that new whale sharks are mainly identified in the later survey sessions, when the waters are already saturated with uyap, could be 
an indication that whale sharks rely on chemosensory cues to detect nutrient rich waters. Aquarium-held whale sharks responded to chemical stimuli cues, such as dimethylsulfide (DMS) and homogenised krill, by exhibiting pronounced ingestive and search behaviours, suggesting that olfactory cues may play an important role to locate food in an environment with sparsely distributed resources (Dove 2015). The highly developed olfactory epithelium located in the nares and corresponding processing centre in the brain further support this hypothesis (Dove 2015). The use of chemosensory cues to locate patchily distributed prey over large spatial scales has also been proposed for other wide-ranging marine predators such as the basking shark (Cetorhinus maximus; Sims and Quayle 1998), the wandering albatross (Diomedea exulans; Nevitt et al. 2008), and the bowhead whale (Balaena mysticetus; Thewissen et al. 2011). Currents leading away from the provisioning site could disperse chemosensory cues over a large area and attract new whale sharks which were moving through the area. Of the 3 sharks that were newly identified in the first session, at least one had been sighted at the provisioning site prior the start of our surveys. While provisioning presumably started in September or October 2011, dedicated photo-ID surveys did not start until March 2012, which means that individuals could have been wrongly classified as new sharks.

Once new whale sharks were sighted in the study area, their time of arrival to the study site shifted to earlier sessions within 10 resightings for the 11 sharks studied. These observations were consistent with reports of shorter time of arrival of white sharks (Carcharodon carcharias) to a chumming site in South Africa with increased experience (Johnson and Kock 2006) and anticipation on feeding times in pink whiprays (Himantura fai) in French Polynesia (Gaspar et al. 2008). While our results are not conclusive, they suggest that after the initial discovery of this new feeding site, the sharks may no longer solely rely on the presence of chemosensory cues in the water, but learn and remember the association of this particular site with the presence of food. For example, by creating a cognitive spatial map, sharks may be able to return to the provisioning site even in the absence of chemosensory cues. This would explain why whale sharks with a long resight history showed anticipatory behaviour by appearing at the provisioning site only minutes after the feeder boats entered the area and before provisioning had started. The ability to create spatial maps has been recognised in several elasmobranchs species, including freshwater stingrays (Potamotrygon motoro), bamboo sharks (Chiloscyllium punctatum and C. griseum), Port Jackson sharks (Heterodontus portusjacksoni) and lemon sharks (Negaprion brevirostris) (Edren and Gruber 2005; Schluessel and Bleckmann 2005; Papastamatiou et al. 2011; Schluessel and Bleckmann 2012; Guttridge and Brown 2014). As other large planktivores, whale sharks face a highly dynamic and rapidly changing environment. Sims et al. (2006) suggested that learned responses to previously encountered prey distributions might explain the highly efficient foraging pattern observed in basking sharks.

The main behaviours observed in the interaction area were vertical feeding, followed by horizontal feeding and free swimming. The GEE model indicated that whale sharks were less likely to display vertically feeding with a stronger water current. When the current was strong, 
377

378

379

380

381

382

383

384

whale sharks had to actively swim to counter-act the effect of the current and to maintain their position around the feeder boat, whereas no such energy expense was required in the absence of current, which promoted stationary, vertical feeding. Interestingly, the model showed that the probability of vertical feeding increased with the shark's experience, which is consistent with observations of new individuals mainly displaying passive feeding or surface feeding away from the feeder boats. Nelson \& Eckert (2007) described vertical feeding as part of the natural repertoire of feeding behaviours in whale sharks and their observations suggested that prey abundance may influence which feeding technique was used. The mean zooplankton density during vertical feeding was only a quarter of that during active feeding (Nelson and Eckert 2007). At the provisioning site, only small handfuls of food are provided to lure the shark along the tourist boats. So while the waters are saturated with chemical stimulus plumes released from the uyap, which have been reported to trigger ingestion behaviours in whale sharks (Dove 2015), the actual density of prey in the water is very low. We hypothesise that the increase in vertical feeding in experienced sharks at this provisioning site is a learnt behaviour as a result of conditioning through positive reinforcement. The continuous food rewards offer a strong incentive for the whale sharks to display the wanted behaviours (i.e. trailing behind the feeder boats) and the animals might quickly learn to associate the feeder boats with food to increase their foraging efficiency. Of the three filter feeding shark species, whale sharks are the only species to be able to suction filter feed, or to feed vertically, which requires no forward movement (Nelson and Eckert 2007). It was proposed that this additional foraging technique may allow the whale shark to compensate for its less efficient filter-feeding apparatus compared to that of the basking and megamouth shark (Heyman et al. 2001; Nelson and Eckert 2007). Whale sharks are known to have a very plastic feeding behaviour and to opportunistically feed on a variety of prey species and sizes, an ability which may allow them to optimise foraging in largely nutrient poor tropical waters (Heyman et al. 2001; Rohner et al. 2015). Feeding techniques such as vertical feeding require a high level of coordination, which might explain the large and highly foliated cerebellum in whale sharks, indeed one of the largest cerebellums within the chondrichthyan clade, which is thought to be involved in modulation of motor programs, self-motion error correction, and dynamic state estimation for coordination of target tracking (Yopak and Frank 2009).

It should be noted that by choosing the first shark the researcher encountered as focal follow shark, free swimming whale sharks at the deeper, more offshore edge of the interaction area were less likely to be included in the data set. Observations were therefore biased towards sharks with high visitation rates. However, the bias that was potentially introduced through the sampling regime was not expected to have an effect on the interpretation of results as our primary interests were sharks that regularly returned to the provisioning site and interacted with the feeders and tourists.

In addition to modification of feeding behaviour through associative learning, the GLMM provided evidence for changes in the avoidance behaviour of the whale sharks with longer re- 
416 sighting histories. Experienced sharks were less likely to show responsive behaviour to actions 417 such as active or passive human contacts and shark-to-shark contact, indicating that the animals 418 became habituated over time. Habituation was defined as a reduction of response to a repeated 419 stimulus, as individuals learn that there are neither adverse nor beneficial consequences of the occurrence of the stimulus (Humphrey 1933). Organisms are constantly exposed to a myriad of sensations and habituation allows them to filter out irrelevant stimuli and to focus on important ones (Rankin et al. 2009). By habituating to physical contacts with humans and other sharks, whale sharks can maximise time spent feeding. In this case, the response to the stimulus was often followed by a food reward, which is why the observed increase in tolerance levels may partially be the result of conditioning, rather than habituation in its pure sense (Bejder et al. 2009). Sharks were most likely to show a response when they were free swimming, in which case their behaviour was not reinforced by provision of food, while they were least likely to show avoidance while they were vertically feeding. In terms of energetic costs, breaking out of the vertical position to swim off is likely more costly than showing avoidance while already swimming freely. The stimulus that elicited the strongest response was shark-to-shark contact, which often resulted in sharks violently thrashing and swimming off. The underlying cause for this strong reaction is not known and could be related to social hierarchy, aggression, or discomfort of physical contact. However, the population in Oslob was described as a maledominated aggregation of juvenile whale sharks (Araujo et al. 2014) and neither size nor sex were significant predictors of avoidance behaviour. $R$. typus is described as a far-ranging, solitary species, which forms almost sex-segregated seasonal aggregations in connection to specific productivity events (Heyman et al. 2001; Rowat and Brooks 2012). As solitary animals, direct body contact might just not be part of their daily social behaviour, but observations on the occurrence of intra-specific body contacts are required to fully understand the strong responsive behaviour. The second strongest stimulus to cause a behavioural response was active touches by guests, such as grabbing the dorsal or caudal fin. In contrast, accidental touches with guests and contacts with boats and the feeder did not elicit a strong behavioural response. Quiros (2007) found that active touches by people were a significant predictor of the occurrence of violent shuddering in whale shark during free swimming encounters in Donsol. These results show the importance of the enforcement of the code of conduct.

The assessment of the compliance to the code of conduct revealed very low adherence to the regulations in place in Oslob. Most worrying was the decreasing trend of compliance from $21.4 \%$ in 2012 to only $3.4 \%$ compliance in 2014 in terms of minimal distance to the whale shark. In comparison, the compliance to a minimum distance of $3 \mathrm{~m}$ to the head and $4 \mathrm{~m}$ to the tail for whale sharks in Donsol was reported to be $44 \%$ in 2005 (Quiros 2007). Our numbers are conservative because only people within $2 \mathrm{~m}$ of the shark were included in the count, whereas the code of conduct regulating the whale shark watching activities in Oslob dictates a minimum distance of $5 \mathrm{~m}$ from the side and tail of the sharks, which means that the real compliance might have been even lower. Free swimming, snorkelling guests tended to have lower compliance than 455 guests holding on to the boat while watching the shark underwater. Snorkelers can control the 
456

457

458

459

460

461

462

463

464

465

466

467

468

469

470

471

472

473

474

475

476

477

478

479

480

481

482

483

484

485

486

487

488

489

490

491

492

493

494

495

distance to the shark by either actively approaching the animal or swimming away to keep the required distance; nevertheless $85 \%$ of snorkelers were too close to the shark in 2014 . Boatholders, in contrast, have little control on the proximity to the shark. The fact that in over threequarters of the cases boat-holders were too close to the shark in 2014 highlighted the problem that feeders lure the sharks too close to the guest boats. Scuba divers complied with the minimum distance regulation in $74 \%$ cases in 2012 and $80 \%$ in 2014. Observations further confirmed that crowding around sharks happened regularly. While the ordinance does not specifically state at what distance a guest is considered to interact with the sharks, the maximum number of six people per shark within $10 \mathrm{~m}$ of the shark was exceeded in over half of the surveys. There is currently no limit on the number of guests in the interaction area at any one time. Feeders bringing the sharks too close to the tourists could be a result of attempting to improve customer satisfaction. However, while visitors in Ningaloo Reef listed proximity to the whale sharks as a secondary important component of their experience, closeness to the sharks did not affect the overall satisfaction (Davis et al. 1997). Similarly, in whale watching, the actual presence of whales and their behaviour, rather than the proximity of the tour boats to the cetaceans, had an important influence on whale watcher satisfaction (Orams 2000). In contrast, crowded situations with too many people in the water with physical contact between tourists generally contributed to bad experiences (Davis et al. 1997).

Overall the poor level of compliance to the code of conduct suggests that the tourism pressure on whale sharks in Oslob is very high. Importantly, the observed increase in tolerance levels in experienced whale sharks should not be misinterpreted as a lack of impact (Bejder et al. 2009). While the behavioural response to disturbance was reduced in experienced whale sharks, this does not exclude costs occurring at the physiological level. The costs of group-living in a normally solitary forager were described in detail for the southern stingray (Dasyatis Americana; Semeniuk \& Rothley 2008; Semeniuk et al. 2009). Along with increased injuries and ectodermal parasites, haematological changes and sub-optimal health were reported for the provisioned animals (Semeniuk et al. 2009). We are currently investigating whether the whale sharks being provisioned at Oslob are affected in a similar way by studying their frequency and accumulation of scars. Araujo et al. (2014) provided evidence for prolonged residency times of provisioned whale sharks in Oslob with unknown consequences on this otherwise highly mobile species. While in natural whale shark aggregations animals increase residency to exploit ephemeral bursts in local productivity until foraging is no longer cost-effective, the food source in Oslob is constant and inexhaustible. At this stage it is still unclear how the previously reported increased residency times in combination with the observed occurrence of conditioning of whale sharks in Oslob may affect the fitness of individual whale sharks. Two possible outcomes can be envisaged: either animals that return regularly fall into an 'ecological trap' with the costs of the new habitat outweighing the apparent benefits (Schlaepfer et al. 2002), or individuals may have identified a predictable, year-round food source that will allow them to grow successfully to maturity without the cost of large-scale movements between other ephemeral foraging areas. Further research should focus on physiological stress levels, body conditions, and diets of 
496

497

498

499

500

501

502

503

504

505

506

507

508

509

510

511

512

513

514

515

516

517

518

519

520

521

522

523

524

525

526

527

528

529

530

531

532

provisioned whale sharks in comparison to non-provisioned whale sharks to reveal additional costs and effects on fitness. In terms of recruitment into this aggregation, it would be interesting to study intraspecific differences in stress threshold levels as a predictor for subsequent visitation patterns. It is currently unclear how conditioning in terms of feeding and avoidance patterns may affect the behaviour of whale sharks outside the interaction area. A continued association between boats and food could be detrimental to the whale sharks and lead to increased injuries by boat strikes (Speed et al. 2008). If provisioning had a permanent effect on whale sharks through conditioning, the activities at the study site would no longer fit the initial definition of a non-consumptive wildlife activity as proposed by Duffus \& Dearden (1993).

Our results indicated that a reduction in tourism pressure and in reinforcement through provisioning would help to minimise the impact on whale shark behaviour. An improved enforcement of the current code of conduct as well as managing the expectations of the visitors will be a key component in increasing compliance to the ordinance while maintaining customer satisfaction. Additionally, limiting the number of people per boat and the total number of boats in the interaction area would reduce crowding. Feeders should be advised to keep a minimum distance of $5 \mathrm{~m}$ to the guest boats. This study highlights the need to consider the past history of a shark when developing codes of conduct, because sharks may show different avoidance behaviours depending on previous experiences with similar stimuli. If possible, codes of conduct based on the precautionary principle should therefore focus on individuals whose behaviour has not been modified through conditioning. While the effects of the observed behavioural modifications on the fitness of the whale sharks remain unclear, the precautionary principle suggests that preventive actions should be taken even if some cause and effect relationships are still unclear (Kriebel et al. 2001).

Overall the results of this study showed that the provisioned whale sharks were capable of adapting their behaviour to a novel food source and increasing their tolerance of potentially disturbing human stimuli. That is why learning leading to behavioural modification is suggested to play an important role in the ecology and feeding plasticity of the whale shark. However, further research is required to test the hypothesis that the initial recruitment of whale sharks to an aggregation is based on chemosensory cues and that the sharks rely on a cognitive spatial map to return to the same feeding site on subsequent occasions.

\section{Acknowledgments}

This work would not have been possible without the help of the Large Marine Vertebrates Project Philippines volunteers (www.lamave.org) and the dedicated work of our staff members, namely Sally Snow, Catherine Lee So, Diana Scalfati, Joseph Murray and Ryan Murray. We'd like to thank the Municipality of Oslob, TOWSFA People's Organisation, The Department of Environment and Natural Resources - Region 7, The Department of Agriculture - Bureau of Fisheries and Aquatic Resources - Region 7, and Wildbook for Whale Sharks 
533 (www.whaleshark.org). A special thank you extends to Dr Jordan Thomson for improving the 534 manuscript and offering advice on statistical analysis.

535

536

537

538

539

540

541

542

543

544

545

546

547

548

549

550

551

552

553

554

555

556

557

558

559

560

561

562

563

564

565

566

\section{References}

Alava, M., Dolumbalo, E., Yaptinchay, A., and Trono, R. (2002). Fishery and trade of whale sharks and manta rays in the Bohol Sea, Philippines. In Elasmobranch Biodiversity, Conservation and Management: Proceedings of the International Seminar and Workshop, Sabah, Malaysia, July 1997, Fowler SL, Reed TM, Dipper FA (ed. IUCN: Gland, Switzerland and Cambridge, UK, 132-148.

Altmann, J. (1974). Observational study of behavior: sampling methods. Behaviour 49, 227-267.

Araujo, G., Lucey, A., Labaja, J., So, C. L., Snow, S., and Ponzo, A. (2014). Population structure and residency patterns of whale sharks, Rhincodon typus, at a provisioning site in Cebu, Philippines. PeerJ 2, e543. doi:10.7717/peerj.543

Babyak, M. (2009). Rescaling continuous predictors in regression models. Rescaling continuous predictors in regression models. Available at http://stattips.blogspot.com/2009/08/rescaling-continuous-predictors-in.html (accessed 24 June 2015).

Bailey, H., Corkrey, R., Cheney, B., and Thompson, P. M. (2013). Analyzing temporally correlated dolphin sightings data using generalized estimating equations. Marine Mammal Science 29, 123-141. doi:10.1111/j.1748-7692.2011.00552.x

Bates, D., Mächler, M., Bolker, B., and Walker, S. (2014). Fitting linear mixed-effects models using lme4. arXiv preprint arXiv:1406.5823.

Bejder, L., Samuels, A., Whitehead, H., Finn, H., and Allen, S. (2009). Impact assessment research: use and misuse of habituation, sensitisation and tolerance in describing wildlife responses to anthropogenic stimuli. Marine Ecology Progress Series 395, 177-185. doi:10.3354/meps07979

Bolker, B., Brooks, M., and Clark, C. (2009). Generalized linear mixed models: a practical guide for ecology and evolution. Trends in ecology \& evolution 24, 127-135.

Bradshaw, C. J. A., Mollet, H. F., and Meekan, M. G. (2007). Inferring population trends for the world's largest fish from mark-recapture estimates of survival. The Journal of animal ecology 76, 480-9. doi:10.1111/j.1365-2656.2006.01201.x

Brena, P., Mourier, J., Planes, S., and Clua, E.(in press) Shark and ray provisioning: functional insights into behavioral, ecological and physiological responses across multiple scales. Marine Ecology Progress Series.

Brunnschweiler, J. M., Abrantes, K. G., and Barnett, A. (2014). Long-term changes in species 
567

568

569

570

571

572

573

574

575

576

577

578

579

580

581

582

583

584

585

586

587

588

589

590

591

592

593

594

595

596

597

598

599

600

composition and relative abundances of sharks at a provisioning site. PloS one $\mathbf{9}$, e86682. doi:10.1371/journal.pone.0086682

Brunnschweiler, J. M., and Baensch, H. (2011). Seasonal and Long-Term Changes in Relative Abundance of Bull Sharks from a Tourist Shark Feeding Site in Fiji. PLoS ONE 6, e16597. doi:10.1371/journal.pone.0016597

Brunnschweiler, J. M., and Barnett, A. (2013). Opportunistic visitors: long-term behavioural response of bull sharks to food provisioning in Fiji. PloS one 8, e58522. doi:10.1371/journal.pone.0058522

Burgin, S., and Hardiman, N. (2015). Effects of non-consumptive wildlife-oriented tourism on marine species and prospects for their sustainable management. Journal of Environmental Management 151, 210-220. doi:10.1016/j.jenvman.2014.12.018

Clua, E., Buray, N., Legendre, P., Mourier, J., and Planes, S. (2010). Behavioural response of sicklefin lemon sharks Negaprion acutidens to underwater feeding for ecotourism purposes. Marine Ecology Progress Series 414, 257-266. doi:10.3354/meps08746

Davis, D., Banks, S., Birtles, A., Valentine, P., and Cuthill, M. (1997). Whale sharks in Ningaloo Marine Park: managing tourism in an Australian marine protected area. Tourism Management 18, 259-271. doi:10.1016/S0261-5177(97)00015-0

Dawson, S. M., and Lusseau, D. (2005). Pseudoreplication problems in studies of dolphin and porpoise reactions to pingers. Marine Mammal Science 21, 175-176.

Dove, A. (2015). Foraging and Ingestive Behaviors of Whale Sharks, Rhincodon typus, in Response to Chemical Stimulus Cues. The Biological Bulletin, 65-74.

Duffus, D., and Dearden, P. (1993). Recreational use, valuation, and management, of killer whales (Orcinus orca) on Canada's Pacific coast. Environmental Conservation 20, 149-156.

Eckert, S. A., Dolar, L. L., Kooyman, G. L., Perrin, W., and Rahman, R. A. (2002). Movements of whale sharks (Rhincodon typus) in South-east Asian waters as determined by satellite telemetry. Journal of Zoology 257, 111-115. doi:10.1017/S0952836902000705

Edren, S., and Gruber, S. H. (2005). Homing ability of young lemon sharks, Negaprion brevirostris. Environmental Biology of Fishes 72, 267-281.

Fitzpatrick, R., Abrantes, K. G., Seymour, J., and Barnett, A. (2011). Variation in depth of whitetip reef sharks: does provisioning ecotourism change their behaviour? Coral Reefs 30, 569-577. doi:10.1007/s00338-011-0769-8

Gallagher, A. J., and Hammerschlag, N. (2011). Global shark currency: the distribution, frequency, and economic value of shark ecotourism. Current Issues in Tourism 14, 797812. doi:10.1080/13683500.2011.585227 
601

602

603

604

605

606

607

608

609

610

611

612

613

614

615

616

617

618

619

620

621

622

623

624

625

626

627

628

629

630

631

632

633

634

635

Gallagher, A. J., Vianna, G. M. S., Papastamatiou, Y. P., Macdonald, C., Guttridge, T. L., and Hammerschlag, N. (2015). Biological effects, conservation potential, and research priorities of shark diving tourism. Biological Conservation 184, 365-379. doi:10.1016/j.biocon.2015.02.007

Gaspar, C., Chateau, O., and Galzin, R. (2008). Feeding sites frequentation by the pink whipray Himantura fai in Moorea ( French Polynesia ) as determined by acoustic telemetry by. Cybium 32, 153-164.Gruber, S. H., and Myrberg, A. A. (1977). Approaches to the Study of the Behavior of Sharks. Integrative and Comparative Biology 17, 471-486. doi:10.1093/icb/17.2.471

Guttridge, T. L., and Brown, C. (2014). Learning and memory in the Port Jackson shark, Heterodontus portusjacksoni. Animal cognition 17, 415-25. doi:10.1007/s10071-013-06734

Guttridge, T. L., Myrberg, A. A., Porcher, I. F., Sims, D. W., and Krause, J. (2009). The role of learning in shark behaviour. Fish and Fisheries 10, 450-469. doi:10.1111/j.14672979.2009.00339.x

Hammerschlag, N., Gallagher, A. J., Wester, J., Luo, J., and Ault, J. S. (2012). Don't bite the hand that feeds: assessing ecological impacts of provisioning ecotourism on an apex marine predator. Functional Ecology 26, 567-576. doi:10.1111/j.1365-2435.2012.01973.x

Haskell, P. J., McGowan, A., Westling, A., Méndez-Jiménez, A., Rohner, C. A., Collins, K., Rosero-Caicedo, M., Salmond, J., Monadjem, A., Marshall, A. D., and Pierce, S. J. (2014). Monitoring the effects of tourism on whale shark Rhincodon typus behaviour in Mozambique. Oryx, 1-8. doi:10.1017/S0030605313001257

Heyman, W., Graham, R., Kjerfve, B., and Johannes, R. (2001). Whale sharks Rhincodon typus aggregate to feed on fish spawn in Belize. Marine Ecology Progress Series 215, 275-282. doi: $10.3354 / \operatorname{meps} 215275$

Højsgaard, S., Halekoh, U., and Yan, J. (2006). The R Package geepack for Generalized Estimating Equations Journal of Statistical Software. 15, 1-11.

Humphrey, G. (1933). The Nature of Learning in Relation to Living Systems. In 'Kegan Paul, Trench \& Trubner: London'.

Hurlbert, S. (1984). Pseudoreplication and the design of ecological field experiments. Ecological monographs 54, 187-211.

Johnson, R., and Kock, A. (2006). South Africa's White Shark cage-diving industry - is their cause for concern? In Nel DC \& Peschak TP (eds) Finding a balance: White shark conservation and recreational safety in the inshore waters of Cape Town, South Africa; proceedings of a specialist workshop. WWF South, 40-59. 
636

637

638

639

640

641

642

643

644

645

646

647

648

649

650

651

652

653

654

655

656

657

658

659

660

661

662

663

664

665

666

667

668

669

Kawecki, T. J. (2010). Evolutionary ecology of learning: Insights from fruit flies. Population Ecology 52, 15-25.

Kriebel, D., Tickner, J., Epstein, P., Lemons, J., Levins, R., Loechler, E. L., Quinn, M., Rudel, R., Schettler, T., and Stoto, M. (2001). Commentaries The Precautionary Principle in Environmental Science. 109, 871-876.

Liang, K., and Zeger, S. (1986). Longitudinal data analysis using generalized linear models. Biometrika 73, 13-22.

Lieberman, D. A. (2000). Learning: Behaviour and cognition. Wadsworth/Thomson Learning.

Maljković, A., and Côté, I. M. (2011). Effects of tourism-related provisioning on the trophic signatures and movement patterns of an apex predator, the Caribbean reef shark. Biological Conservation 144, 859-865. doi:10.1016/j.biocon.2010.11.019

Mann, J., and Würsig, B. (2014). Observing and Quantifying Cetacean Behavior in the Wild: Current Problems, Limitations, and Future Directions Eds J. Yamagiwa and L. Karczmarski. Primates and Cetaceans: Field Research and Conservation of Complex Mammalian Societies, Primatology Monographs, 335-344. doi:10.1007/978-4-431-54523-1

Nelson, J. D., and Eckert, S. A. (2007). Foraging ecology of whale sharks (Rhincodon typus) within Bahía de Los Angeles, Baja California Norte, México. Fisheries Research 84, 4764. doi:10.1016/j.fishres.2006.11.013

Nevitt, G. a, Losekoot, M., and Weimerskirch, H. (2008). Evidence for olfactory search in wandering albatross, Diomedea exulans. Proceedings of the National Academy of Sciences of the United States of America 105, 4576-81. doi:10.1073/pnas.0709047105

Orams, M. B. (2002). Feeding wildlife as a tourism attraction: a review of issues and impacts. Tourism Management 23, 281-293. doi:10.1016/S0261-5177(01)00080-2

Orams, M. B. (2000). Tourists getting close to whales, is it what whale-watching is all about? 21, 561-569.

Panigada, S., Zanardelli, M., MacKenzie, M., Donovan, C., Mélin, F., and Hammond, P. S. (2008). Modelling habitat preferences for fin whales and striped dolphins in the Pelagos Sanctuary (Western Mediterranean Sea) with physiographic and remote sensing variables. Remote Sensing of Environment 112, 3400-3412. doi:10.1016/j.rse.2007.11.017

Papastamatiou, Y. P., Cartamil, D. P., Lowe, C. G., Meyer, C. G., Wetherbee, B. M., and Holland, K. N. (2011). Scales of orientation, directed walks and movement path structure in sharks. Journal of Animal Ecology 80, 864-874. doi:10.1111/j.13652656.2011.01815.xPierce, S. J., Méndez-Jiménez, A., Collins, K., Rosero-Caicedo, M., and Monadjem, A. (2010). Developing a Code of Conduct for whale shark interactions in 
670

671

672

673

674

675

676

677

678

679

680

681

682

683

684

685

686

687

688

689

690

691

692

693

694

695

696

697

698

699

700

701

702

703

Mozambique. Aquatic Conservation: Marine and Freshwater Ecosystems 20, 782-788. doi:10.1002/aqc.1149

Quiros, A. L. (2007). Tourist compliance to a Code of Conduct and the resulting effects on whale shark (Rhincodon typus) behavior in Donsol, Philippines. Fisheries Research 84, 102-108. doi:10.1016/j.fishres.2006.11.017

R Core Team (2014). R: A language and environment for statistical computing. $R$ Foundation for Statistical Computing, Vienna, Austria. URL http://www.R-project.org/.

Rankin, C. H., Abrams, T., Barry, R. J., Bhatnagar, S., Clayton, D. F., Colombo, J., Coppola, G., Geyer, M. a., Glanzman, D. L., Marsland, S., McSweeney, F. K., Wilson, D. a., Wu, C. F., and Thompson, R. F. (2009). Habituation revisited: An updated and revised description of the behavioral characteristics of habituation. Neurobiology of Learning and Memory 92 , 135-138. doi:10.1016/j.nlm.2008.09.012

Richards, K., O’Leary, B. C., Roberts, C. M., Ormond, R., Gore, M., and Hawkins, J. P. (2015). Sharks and people: Insight into the global practices of tourism operators and their attitudes to Shark behaviour. Marine pollution bulletin 91, 200-10. doi:10.1016/j.marpolbul.2014.12.004

Rohner, C. A., Armstrong, A. J., Pierce, S. J., Prebble, C. E. M., Cagua, E. F., Cochran, J. E. M., Berumen, M. L., and Richardson, A. J. (2015). Whale sharks target dense prey patches of sergestid shrimp off Tanzania. Journal of plankton research 37, 352-362. doi:10.1093/plankt/fbv010

Rowat, D., and Brooks, K. S. (2012). A review of the biology, fisheries and conservation of the whale shark Rhincodon typus. Journal of fish biology 80, 1019-56. doi:10.1111/j.10958649.2012.03252.x

Schlaepfer, M. A., Runge, M. C., and Sherman, P. W. (2002). Ecological and evolutionary traps. Trends in Ecology \& Evolution 17, 474-480. doi:10.1016/S0169-5347(02)02580-6

Schluessel, V. (2015). Who would have thought that 'Jaws' also has brains? Cognitive functions in elasmobranchs. Animal cognition 18, 19-37. doi:10.1007/s10071-014-0762-z

Schluessel, V., and Bleckmann, H. (2012). Spatial learning and memory retention in the grey bamboo shark (Chiloscyllium griseum). Zoology 115, 346-353.

Schluessel, V., and Bleckmann, H. (2005). Spatial memory and orientation strategies in the elasmobranch Potamotrygon motoro. Journal of Comparative Physiology A: Neuroethology, Sensory, Neural, and Behavioral Physiology 191, 695-706.

Semeniuk, C. A. D., Bourgeon, S., Smith, S. L., and Rothley, K. D. (2009). Hematological differences between stingrays at tourist and non-visited sites suggest physiological costs of 
722

723

724

725

726

727

728

729

730

731 732

wildlife tourism. Biological Conservation 142, 1818-1829.

doi:10.1016/j.biocon.2009.03.022

Semeniuk, C., and Rothley, K. (2008). Costs of group-living for a normally solitary forager: effects of provisioning tourism on southern stingrays Dasyatis americana. Marine Ecology Progress Series 357, 271-282. doi:10.3354/meps07299

Sims, D. W., Witt, M. J., Richardson, A. J., Southall, E. J., and Metcalfe, J. D. (2006). Encounter success of free-ranging marine predator movements across a dynamic prey landscape. Proceedings. Biological sciences / The Royal Society 273, 1195-201. doi:10.1098/rspb.2005.3444

Smith, K., Scarr, M., and Scarpaci, C. (2010). Grey nurse shark (Carcharias taurus) diving tourism: Tourist compliance and shark behaviour at Fish Rock, Australia. Environmental management 46, 699-710. doi:10.1007/s00267-010-9561-8

Speed, C. W., Meekan, M. G., Rowat, D., Pierce, S. J., Marshall, A. D., and Bradshaw, C. J. A. (2008). Scarring patterns and relative mortality rates of Indian Ocean whale sharks. Journal of Fish Biology 72, 1488-1503. doi:10.1111/j.1095-8649.2008.01810.x

Thewissen, J. G. M., George, J., Rosa, C., and Kishida, T. (2011). Olfaction and brain size in the bowhead whale (Balaena mysticetus). Marine Mammal Science 27, 282-294. doi:10.1111/j.1748-7692.2010.00406.x

Vianna, G. M. S., Meekan, M. G., Pannell, D. J., Marsh, S. P., and Meeuwig, J. J. (2012). Socioeconomic value and community benefits from shark-diving tourism in Palau: A sustainable use of reef shark populations. Biological Conservation 145, 267-277. doi:10.1016/j.biocon.2011.11.022

Yan, J. (2002). geepack: Yet Another Package for Generalized Estimating Equations. R-News $\mathbf{2 / 3}, 12-14$.

Yopak, K. E., and Frank, L. R. (2009). Brain size and brain organization of the whale shark, Rhincodon typus, using magnetic resonance imaging. Brain, behavior and evolution 74, 121-42. doi:10.1159/000235962

Zuur, A. F., Ieno, E. N., Walker, N., Saveliev, A. A., and Smith, G. M. (2009). Mixed Effects Models and Extensions in Ecology with R. Statistics for Biology and Health, 579pp. 


\section{Table $\mathbf{1}$ (on next page)}

Definitions of the predominant behaviour as recorded on a 5 minute basis during focal follows of whale sharks, as well as definitions of events and subsequent reactions. 


\begin{tabular}{|c|c|}
\hline $\begin{array}{l}\text { Predominant } \\
\text { Behaviour }\end{array}$ & Definition \\
\hline Horizontal feeding & $\begin{array}{l}\text { Shark actively swims behind feeder boats with its body angled } \\
\text { horizontally (variation of angle depending on speed of current and } \\
\text { feeder boats). }\end{array}$ \\
\hline Vertical feeding & $\begin{array}{l}\text { Shark is in a stationary position, with its body in a vertical } \\
\text { orientation with its mouth just below the water surface. Food is } \\
\text { ingested by gulping water using a suction technique. }\end{array}$ \\
\hline Natural feeding & $\begin{array}{l}\text { Shark swims with either partially or totally open mouth } \\
\text { displaying passive or active feeding in an area away from the } \\
\text { feeder boats. }\end{array}$ \\
\hline Free swimming & $\begin{array}{l}\text { Shark swims with mouth closed, independently of feeder boat } \\
\text { proximity. }\end{array}$ \\
\hline \multicolumn{2}{|r|}{ 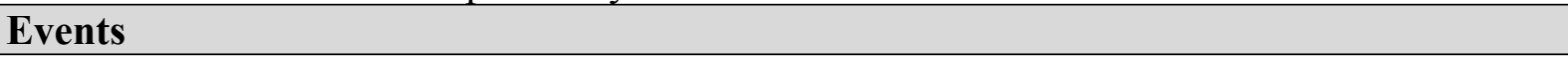 } \\
\hline Active touch & $\begin{array}{l}\text { Guest intentionally approaches the animal and initiates shark } \\
\text { contact with any body part or gear (e.g. fins, camera, camera } \\
\text { pole). }\end{array}$ \\
\hline Passive touch & $\begin{array}{l}\text { Any contact between shark and guest where the guest does not } \\
\text { intentionally approach the animal. }\end{array}$ \\
\hline Feeder Contact & $\begin{array}{l}\text { Feeder intentionally touches the shark with any body part or his } \\
\text { paddle. }\end{array}$ \\
\hline Shark-to-Shark contact & Two or more sharks make physical contact \\
\hline Boat Contact & Shark and any boat in the interaction area make physical contact. \\
\hline \multicolumn{2}{|l|}{ Reactions } \\
\hline No reaction & $\begin{array}{l}\text { No evident behavioural change recorded immediately after the } \\
\text { observed event }\end{array}$ \\
\hline Swam off & $\begin{array}{l}\text { Shark changes behaviour abruptly and swims away without depth } \\
\text { variation }\end{array}$ \\
\hline Dive & Shark changes behaviour and descents to greater water depths \\
\hline Bank & $\begin{array}{l}\text { Shark rolls and orientates its dorsal side towards the perceived } \\
\text { threat }\end{array}$ \\
\hline Cough & Shark forcefully expels water and other material out of the mouth \\
\hline Eye roll & Shark rotates eye backward into the eye socket \\
\hline Violent shudder & Shark physically shakes its body \\
\hline
\end{tabular}




\section{Table 2 (on next page)}

Seasonal percentage non-compliance in terms of minimum distance kept to the whale shark and active touches by guests. 
Percentage non-compliance

\begin{tabular}{lrrr}
\hline Regulation & $\begin{array}{r}\mathbf{2 0 1 2} \\
\text { season }\end{array}$ & $\begin{array}{r}\mathbf{2 0 1 3} \\
\text { season }\end{array}$ & $\begin{array}{r}\mathbf{2 0 1 4} \\
\text { season }\end{array}$ \\
\hline Snorkeler closer than 2 m from shark & $65.6 \%$ & $n a$ & $84.9 \%$ \\
Boat- holder closer than 2 m from shark & $54.3 \%$ & $n a$ & $76.5 \%$ \\
Diver keeping closer than 2 m from shark & $26.3 \%$ & $n a$ & $20.2 \%$ \\
Snorkeler and boat-holder closer than 2 m from shark & $78.6 \%$ & $90.7 \%$ & $96.6 \%$ \\
Active touches by guests & $8.7 \%$ & $31.4 \%$ & $14.3 \%$
\end{tabular}
1 


\section{Table 3(on next page)}

Parameter estimates of GLMM on avoidance behaviour with standard errors (s.e.). 


\begin{tabular}{lll}
\hline Fixed effect & Coefficient & s.e. \\
\hline Intercept & -0.21 & 0.74 \\
Number of previous visits & -0.82 & 0.43 \\
Behaviour: Horizontal feeding & -1.29 & 0.56 \\
Behaviour: Vertical feeding & -1.69 & 0.44 \\
Event: Boat contact & 0.46 & 0.71 \\
Event: Feeder contact & 0.22 & 0.91 \\
Event: Active touch & 1.45 & 0.81 \\
Event: Shark-to-shark contact & 2.18 & 0.64 \\
\hline
\end{tabular}

1 
Table 4(on next page)

Results from the generalised estimating equation model with autoregressive correlation structure on the occurrence of vertical feeding. An asterisk indicates significance at $p<$ 0.05 level. 


\begin{tabular}{lrrrr}
\hline Parameter & Coefficient estimate & Standard error & Wald & $\boldsymbol{p}$ \\
\hline Intercept & 0.378 & 0.188 & 4.04 & 0.044 \\
Previous visits & 0.001 & 0.0004 & 13.95 & $<0.001^{*}$ \\
Current & -0.200 & 0.080 & 6.16 & $0.013^{*}$ \\
\hline
\end{tabular}

1 
1

Frequency distribution of maximum number of snorkelers and boat-holders recorded within $10 \mathrm{~m}$ of the whale shark per focal follow.

The red line shows the maximum number of people allowed per shark.

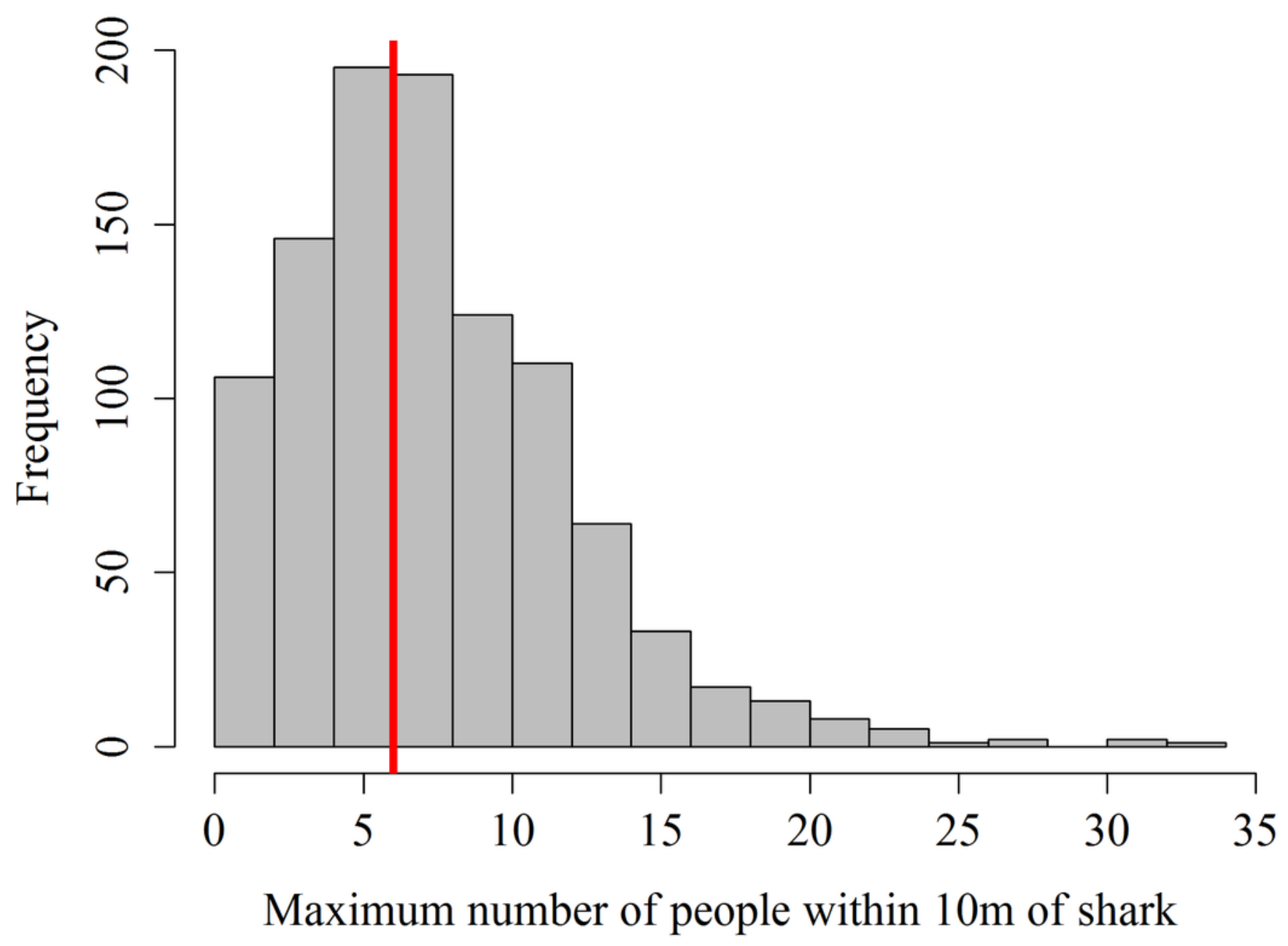


2

GLMM results of the occurrence of avoidance behaviour in relation to the number of previous daily sightings.

(A) Fitted values of GLMM show overall effect of the number of previous visits on the probability of avoidance behaviour with line of best fit; (B) Predicted probability of avoidance behaviour after shark-to-shark contact of a whale shark that is feeding vertically. Shaded area shows $95 \%$ confidence interval.
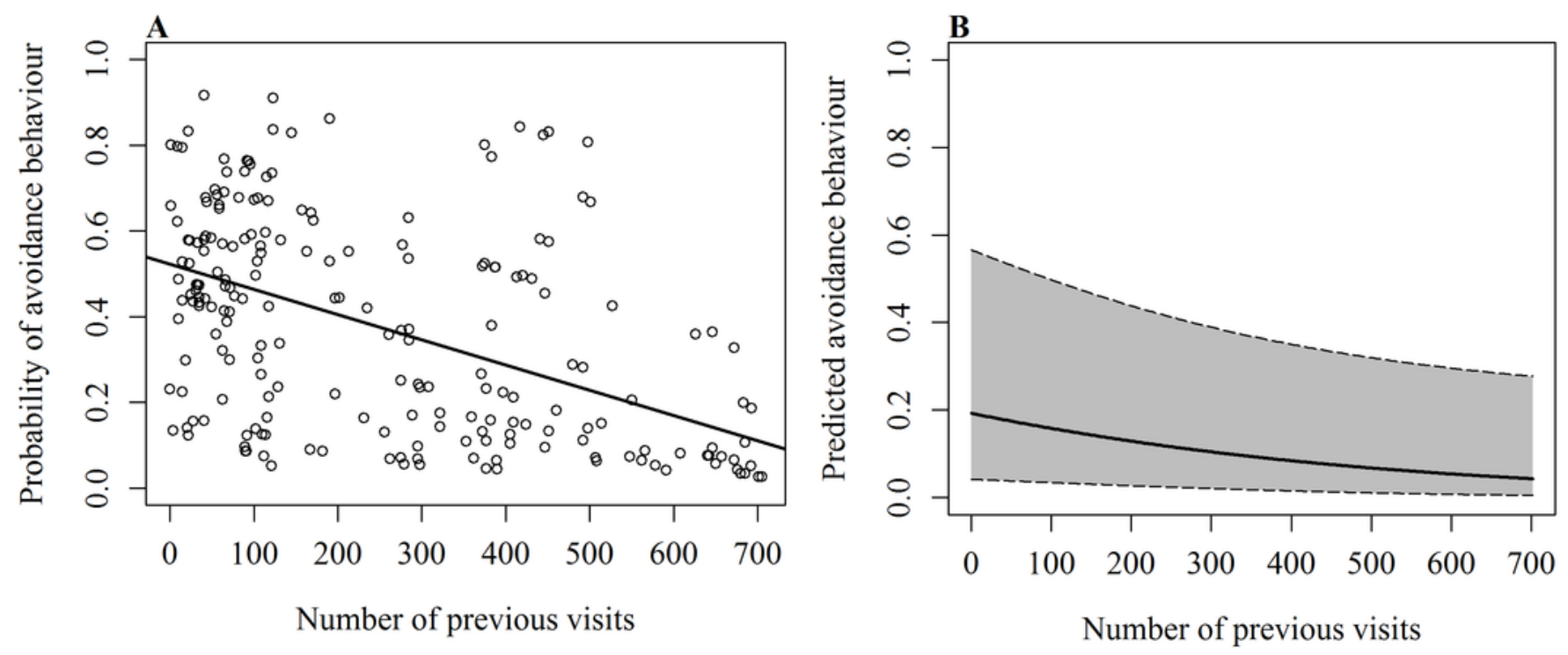
3

Predicted values of vertical feeding occurrence from GEE model against number of previous daily sightings with $95 \%$ confidence intervals.

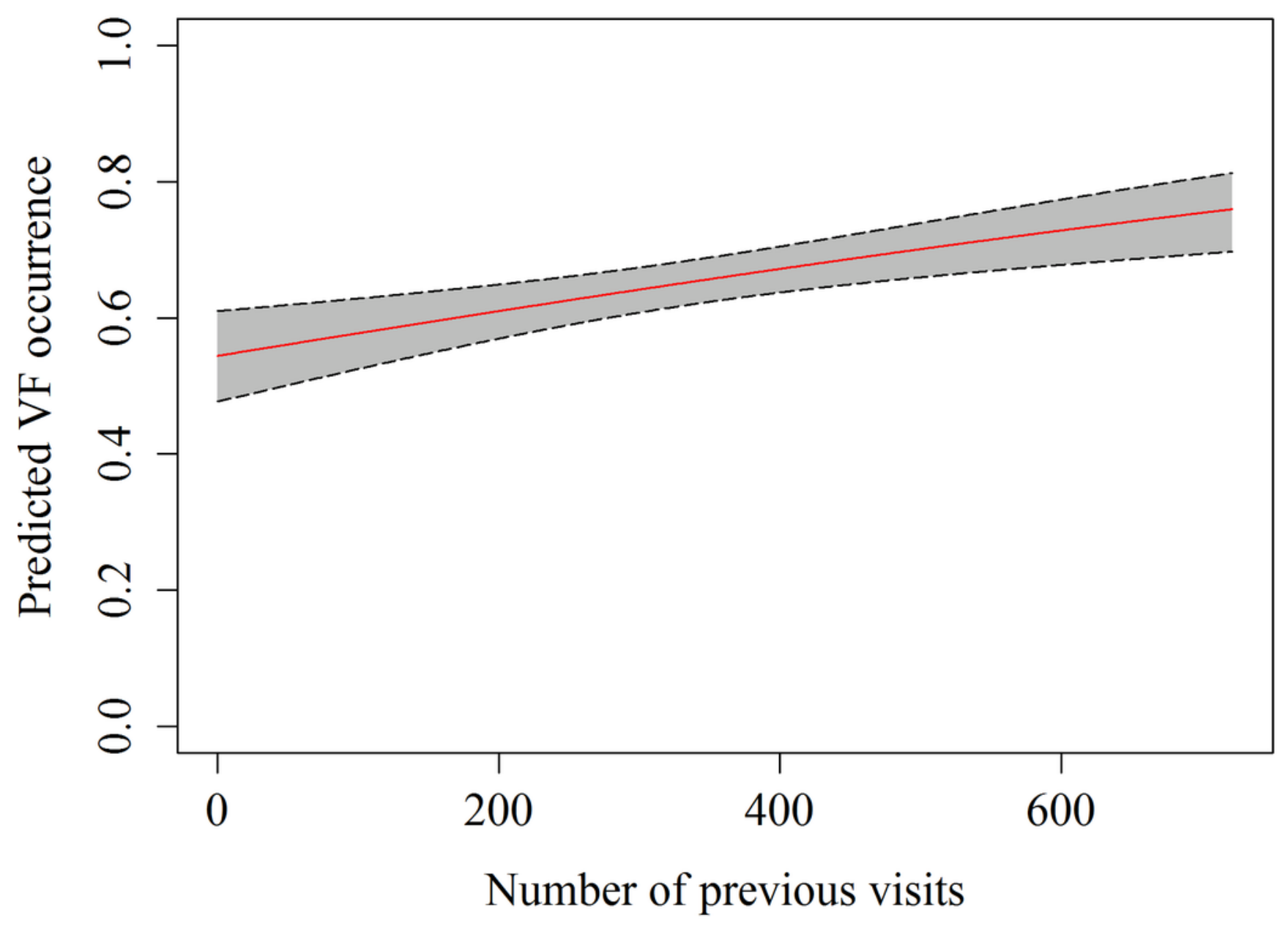


4

Total number of previously unidentified sharks encountered in each hourly survey session from 6 am to $1 \mathrm{pm}$.

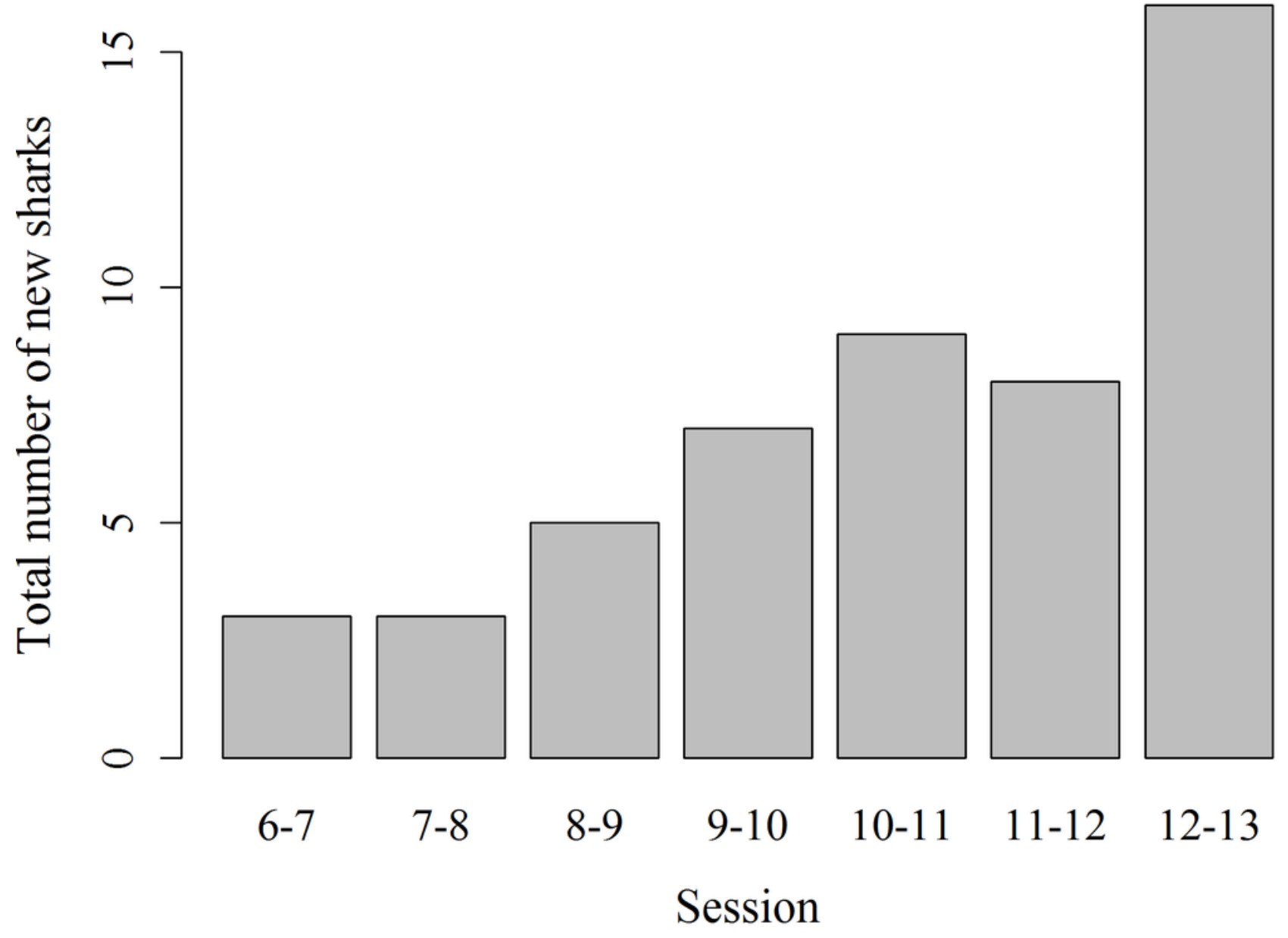


5

Arrival time to the study area of 11 sharks on the 10 sightings following their first appearance in the interaction area.

Lines represent best fit lines for each individual. The trend was negative in all cases and statistically significant in 6 out of 11 cases (statistical tests not shown).

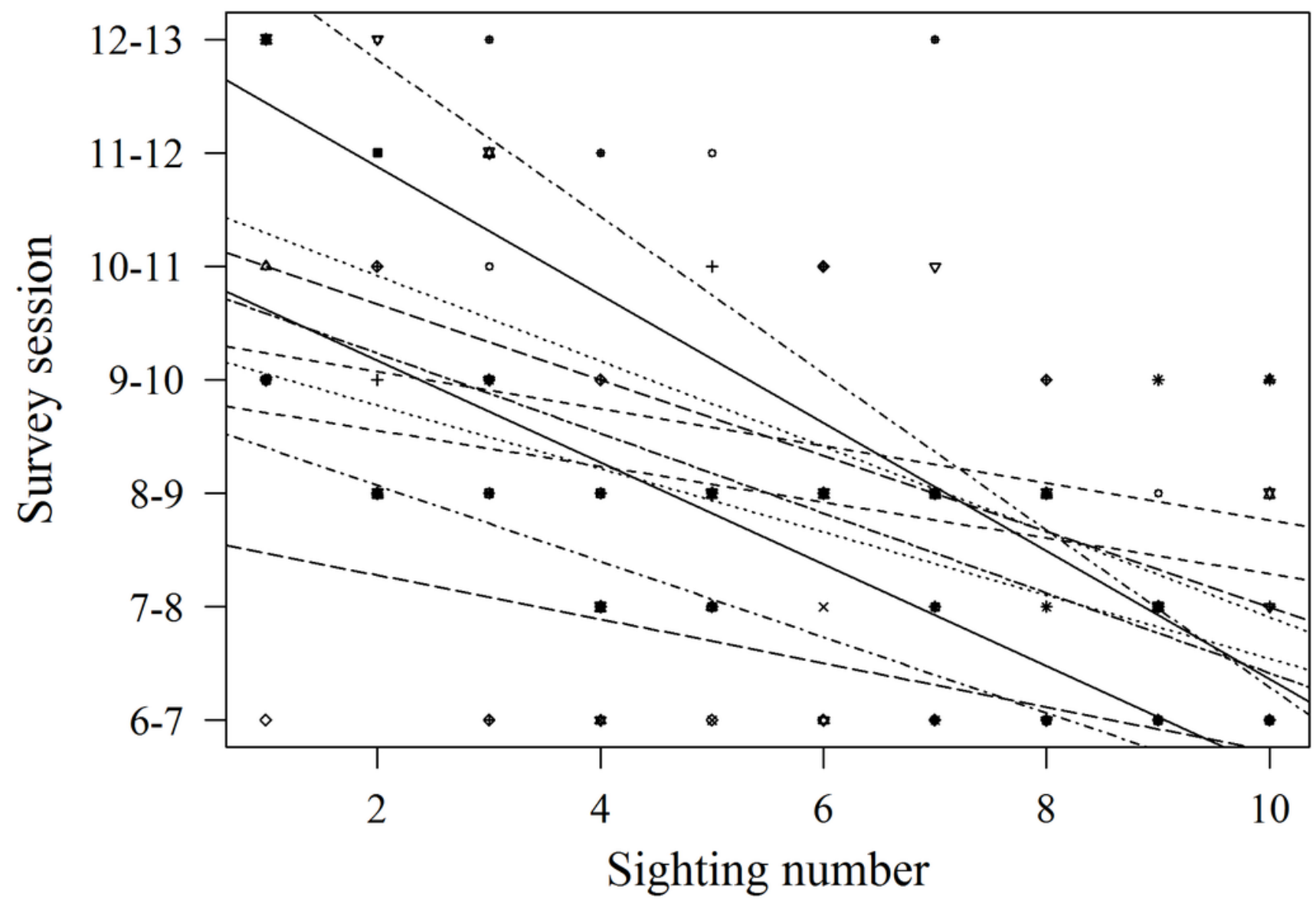

